\title{
Competencia de las prendas de vestir mexicanas en el mercado de Estados Unidos ${ }^{1}$
}

\author{
Nadima Simón Domínguez
}

\section{Resumen}

El objetivo de este artículo es analizar el comportamiento de las exportaciones del sector de prendas de vestir (de tejido de punto y de tejido plano) en el mercado de Estados Unidos (EUA) durante el periodo de 1990 a 2002. Se identifican los principales competidores, las características de ambos mercados y los instrumentos de política comercial utilizados por las empresas estadounidenses para la protección de su industria textil. De igual forma, se hace un análisis de los principales productos de prendas de vestir que nuestro país exportó a EUA clasificándolos por su participación en el mercado de dicho país y por el dinamismo que presentan éstos. También se identifican los factores que inciden en la participación de México en el mercado estadounidense.

Se concluye que México incrementó considerablemente sus exportaciones de prendas de vestir a EUA después de la entrada en vigor del TLCAN y de la devaluación del peso mexicano de diciembre de 1994. México es líder en el mercado de aquel país en camisas de algodón y en pantalones de mezclilla, seguido muy de cerca por China. Para mantener la participación de las prendas de vestir de México en dicho mercado, nuestra industria del vestido debe orientarse a la fabricación de paquete completo y de productos de moda con mayor valor agregado.

Palabras clave: industria de la confección de prendas de vestir, cadenas productivas globales y desempeño exportador.

La competencia de las prendas de vestir mexicanas en el mercado de Estados Unidos es un reto para la industria de nuestro país. El objetivo de este artículo es analizar el comportamiento de las exportaciones del sector de prendas de vestir (de tejido de punto y de tejido plano) al mercado de Estados Unidos (EUA) durante el periodo de 1990 al 2002. Se identifican los principales competidores, las características de ambos mercados y los instrumentos de política comercial utilizados por las empresas de EUA para la protección de su industria textil.

Asimismo, se hace un análisis de los principales productos de prendas de vestir que nuestro país exportó a EUA clasificándolos por su participación en el mercado de dicho país y por el dinamismo que presentan éstos. Asimismo, se identifican los factores que inciden en la participación de México en el mercado estadounidense.

\footnotetext{
${ }^{1}$ Este artículo se elaboró en el marco del proyecto "La inserción de empresas en Aguascalientes y Yucatán en las cadenas productivas de la industria de la confección de prendas de vestir, en el mercado global", el cual recibió financiamiento del Programa de Apoyo a Proyectos de Investigación e Innovación Tecnológica (PAPIIT) de la Dirección General de Asuntos del Personal Académico de la Universidad Nacional Autónoma de México.

*

Investigadora de la División de Investigación de la Facultad de Contaduría y Administración, UNAM. Correo electrónico: nadimasimon@hotmail.com
} 


\section{El mercado de las prendas de vestir en Estados Unidos}

En este apartado se presentan las principales características del mercado de la confección en Estados Unidos, a la luz de las cuales se puede entender mejor el desempeño competitivo de México en dicho mercado.

El problema más grande de la industria de la confección de EUA es el alto costo de la mano de obra. Desde la década de los cincuenta del siglo pasado, las empresas estadounidenses empezaron a trasladar sus operaciones a Japón, Hong Kong, Corea del Sur y Taiwán, mediante contratos de paquete completo ${ }^{2}$. Ante el incremento de los salarios, estos países empezaron a subcontratar en China, Sri Lanka, Tailandia, India, Indonesia, Bangladesh, etc.; la invasión de productos asiáticos empezó a convertirse en una seria amenaza para la industria textil estadounidense, ya que no se fabricaban con tela de EUA.

A partir de 1980, la industria y el gobierno de EUA diseñaron una estrategia tendiente a fortalecer su industria textil mediante el esquema de producción compartida 807/9802 con México y los 24 países beneficiarios de la Iniciativa de la Cuenca del Caribe (ICC); este esquema propició la utilización de telas fabricadas en y contribuyó a la decadencia de la industria textil de México.

La mayoría de las exportaciones de confección de México y de los países de la ICC ingresan al mercado estadounidense al amparo del régimen 9802.00.80 de su sistema arancelario $^{3}$, lo cual refleja la alta dependencia que dichas exportaciones tienen de los insumos estadounidenses, en particular, del uso de tela de ese país. Las empresas de EUA aseguran de esta manera un mayor control de los procesos productivos y de las materias primas que se utilizan en la fabricación de las prendas de vestir. (Buitelaar y Rodríguez, 2000: 5-6). Dicha estrategia se reflejó en diversos instrumentos de política comercial como el Acuerdo de los Textiles y el Vestido (ATV), el Tratado de Libre Comercio de América del Norte (TLCAN) y el Programa de Acceso Especial (Chacón, 2000: 19-20).

\section{El Acuerdo de los Textiles y el Vestido}

El comercio internacional del sector textil y del vestido estuvo controlado por regímenes especiales a partir del Acuerdo del Algodón de corto plazo y largo plazo (1961-1973) y del Acuerdo Multifibras (AMF) de 1974 a 1994. Este último, bajo los auspicios del Acuerdo General de Aranceles y Comercio (GATT, por sus siglas en inglés), tuvo como propósito permitirle a EUA y a la Unión Europea, principalmente, negociar o imponer cuotas contra las importaciones textiles y de la confección provenientes de los países en desarrollo. El AMF terminó el 31 de diciembre de 1994 con la entrada en vigor de la Organización Mundial de Comercio (OMC) y el Acuerdo de los Textiles y el Vestido (ATV) del 1o. de

\footnotetext{
2 Estos países utilizaron el llamado "paquete completo", a través del cual las empresas estadounidenses encargan a sus proveedores la confección de un determinado producto y éstos se responsabilizan de entregar la prenda final de acuerdo con las especificaciones del pedido. Esto provocó el desarrollo de cadenas productivas y la utilización de telas de origen asiático.

${ }^{3}$ Este régimen, anteriormente denominado 807, consiste en que los impuestos de importación se pagan únicamente sobre el valor agregado en el extranjero y no sobre los componentes estadounidenses que se utilizan para el ensamble.
} 
enero de 1995, que fue uno de los resultados más importantes de la VIII Ronda de Negociaciones Comerciales Multilaterales, conocida como la Ronda Uruguay. El ATV contiene las disposiciones para integrar los productos textiles y del vestido a las reglas comunes del GATT y para desmantelar de manera progresiva las restricciones cuantitativas asociadas a este sector; asimismo, incluye disposiciones tendientes a disminuir las prácticas dumping y el incumplimiento de obligaciones del transbordo, las desviaciones en las rutas, la falsa declaración referente al país o lugar de origen y la falsificación de documentos oficiales (Werner, 2003: 38-49).

La integración de productos se programó para un periodo de diez años (1o. de enero de 1995 al 1o. de enero del 2005) que se está realizando en cuatro etapas, cada una de éstas integra un porcentaje específico de productos y la relativa eliminación de cuotas, así como el crecimiento anual de éstas para los productos restantes. De esta manera, una vez que un país integra determinado producto, las restricciones en cuotas sobre su importación desde países miembros de la OMC quedan eliminadas y éstos deberán observar las normas y disposiciones del GATT. EUA se ha reservado las categorías de productos más importantes para la última etapa del programa de integración: pantalones, vestidos, trajes y abrigos de algodón y ropa interior de algodón (Ibidem).

\section{El Tratado de Libre Comercio de América del Norte}

El Tratado de Libre Comercio de América del Norte (TLCAN) entró en vigor el 1o. de enero de 1994. El anexo $300 \mathrm{~B}$ del capítulo III regula el comercio de los productos textiles y de la confección estableciendo la reducción progresiva y gradual de los aranceles a los bienes que cumplan con las reglas de origen de "hilaza en adelante"; lo anterior significa que sólo se les dará el trato preferencial en aranceles a aquellos productos que sean manufacturados a partir del hilo fabricado en EUA, Canadá o México (Chacón, 2000: 2223).

Con la entrada en vigor del TLCAN se inició un proceso que favoreció las exportaciones mexicanas de la indumentaria debido: a) la eliminación de las restricciones al comercio que hicieron que México se dedicara a operaciones de ensamble, ya que con el sistema de maquila el ingreso de las confecciones mexicanas a EUA se condicionó a utilizar insumos estadounidenses; b) eliminación de gravámenes arancelarios en cada una de los procesos de la cadena productiva de la confección como son corte, lavado, costura y bordado, etc., lo cual provocó que se reubicaran cada vez más en México dichos procesos (Gereffi, 2000: 82).

Para México, los principales efectos del TLCAN sobre la industria textil y del vestido fueron un incremento en las exportaciones con el consecuente aumento de divisas convirtiendo a México en uno de los principales proveedores de ropa a EUA y un incremento de maquiladoras de la confección en varios estados de la República Mexicana. Si bien estas empresas crean empleos, también se aprovechan de la mano de obra barata y de buena calidad de nuestro país. El gobierno mexicano ha seguido la política de aumentar las exportaciones vía las maquiladoras, haciendo a la industria inestable porque fácilmente 
cierran sus fábricas y se trasladan a otros países con condiciones para ellas más favorables ${ }^{4}$. Al mismo tiempo, el TLCAN también propició la integración de la industria de la confección mexicana a la textil de EUA y la especialización en ciertas prendas de vestir. De esta manera, puede decirse que la industria de la confección en México cada vez es más vulnerable y dependiente, ya que la recesión de los EUA iniciada en el 2000 ha afectado las exportaciones mexicanas y ha provocado el cierre de plantas maquiladoras, con la consecuente pérdida de empleos (González Marín, 2004).

\section{El Programa de Acceso Especial}

Con la Iniciativa de la Cuenca del Caribe (ICC) que entró en vigor en 1984, 24 países fueron beneficiados con el libre acceso de sus productos al mercado de EUA. Si bien la ICC excluía las prendas de vestir, otros programas garantizaron niveles de acceso y el pago de impuestos únicamente sobre el valor agregado (llamada ley 807), lo que tuvo fuerte impacto en el auge de las exportaciones de estos países al mercado de EUA (Buitelaar y Rodríguez, 2000: 8).

En 1986, EUA puso en vigencia el Programa de Acceso Especial, mediante el cual los productos de la confección provenientes de los países de la ICC que sean ensamblados con tela fabricada y cortada en ese país disfrutarían de cuotas de importación amplias; es decir, de niveles de acceso garantizado. Los artículos similares que no utilizan tela fabricada y cortada en EUA están sujetos a cuotas de importación más reducidas.

El esquema de producción compartida, el Programa de Acceso Especial y el TLCAN han servido como incentivos para promover la inversión directa en los países beneficiados con dichos programas y sobre todo para deteriorar la participación de los proveedores asiáticos y fomentar el uso de telas fabricadas en EUA, fortaleciendo su industria textil y trasladando los procesos de confección a los países con menor costo de mano de obra. Los esquemas de producción compartida permiten a las empresas estadounidenses, que trasladaron sus plantas a estos países, ventajas derivadas de su cercanía a EUA en los costos de transporte y en la posibilidad de reaccionar más rápidamente ante los cambios en la demanda de sus clientes (Chacón, 2000:23-28).

\section{Modelos de competencia}

En las últimas décadas, la industria del vestido se ha convertido en una industria global, lo cual significa que no sólo es internacional en cuanto a su alcance, sino que también lo es en cuanto a su organización. Gereffi (2000: 57-59) señala que la internacionalización no es un fenómeno nuevo en relación con la expansión de las actividades económicas más allá de las fronteras nacionales; mientras que la globalización es más reciente e implica la integración funcional entre actividades dispersas en distintas naciones. Los países desarrollados han promovido la globalización utilizando dos tipos de redes internacionales, las cuales dicho

\footnotetext{
${ }^{4}$ Entre junio de 2001 y diciembre de 2002 salieron de México 322 de estas empresas (28\% del total existente) con la pérdida de 58,729 empleos (Agoitia, 2003).
} 
autor denomina cadenas ${ }^{5}$ globales “impulsadas por el productor" e "impulsadas por el comprador".

Las cadenas globales impulsadas por el productor tienen como principal característica que los grandes productores, generalmente transnacionales, controlen las redes de producción y las vinculaciones hacia atrás y hacia delante de dichas cadenas, que se conforman con miles de empresas controladoras, subsidiarias y subcontratistas. Estas cadenas son características de las industrias intensivas en capital y tecnología como la automotriz y la de maquinaria pesada.

Por su parte, las cadenas globales impulsadas por el comprador están constituidas por industrias en las que empresas minoristas, comercializadoras y fabricantes de marca de países desarrollados desempeñan el papel central en la organización de las cadenas productivas mediante el traslado de la fabricación a los países del tercer mundo. Dichas empresas se convierten en intermediarias, para lo cual utilizan avanzados medios de transporte y de comunicación. En estas cadenas, que son típicas de las industrias intensivas de mano de obra como la del vestido, zapatos, artículos del hogar, etc., el comprador obtiene las mayores ganancias porque controla la cadena al encargarse del diseño, comercialización y servicios financieros de alta calidad. El fabricante controla la producción, pero no los demás procesos de dichas cadenas.

En el caso de la industria mexicana del vestido, el eslabón más débil de la cadena es el sector textil, pues está conformado por empresas tecnológicamente atrasadas que producen telas de mala calidad y el más fuerte es, sin duda, el de la confección. A diferencia de México, EUA es fuerte en la industria textil y débil en el sector de la confección, pues los altos costos de la mano de obra lo hacen poco competitivo.

Según Gereffi (2000), sobresalen tres modelos de competencia en el mercado de prendas de vestir de EUA:

- El modelo del este asiático. Japón, Hong Kong, Taiwán, Corea y China, los países más representativos de este modelo, han utilizado diferentes roles exportadores que van del ensamble a la fabricación del paquete completo y de marcas originales, lo que les permite dominar el mercado de la ropa femenina con alto valor agregado. Estos países desarrollaron su capacidad exportadora mediante transacciones exitosas con los compradores de EUA y en ocasiones se convirtieron en intermediarios entre éstos y fabricantes de otros países asiáticos para aprovechar sus cuotas favorables y menores salarios.

- El modelo mexicano. En éste se observa la transición del ensamble a la producción de paquete completo, la cual se dificulta porque México todavía no tiene la infraestructura de industrias relacionadas y de apoyo que se requieren. Aun cuando las devaluaciones del peso mexicano en 1994 y 1995 originaron que nuestro país se convirtiera en un lugar muy

\footnotetext{
${ }^{5}$ Una cadena se refiere a todo el rango de actividades involucradas en el diseño, la producción y la comercialización de un producto. La cadena completa del vestido comprende materias primas, hilado y fibras sintéticas, textiles, confección y la distribución a los minoristas. (Gereffi, 2000)
} 
atractivo para las empresas estadounidenses textiles y de la confección con operaciones internacionales de subcontratación y las reglas de origen del TLCAN crearon un incentivo para una mayor integración de la fabricación de prendas de vestir, todavía está muy lejos de competir con los proveedores asiáticos de paquete completo. En el modelo mexicano, las empresas transnacionales de EUA controlan los segmentos de diseño y comercialización con marcas globales que dominan la industria, mientras que las empresas mexicanas controlan el segmento de la producción.

- El modelo de la Cuenca del Caribe. Este modelo, que está limitado casi exclusivamente al ensamble de acuerdo con el régimen 807/9802, se basa en bajos salarios, acceso preferencial y en su cercanía a los EUA. Estos países han tenido gran éxito en las operaciones de ensamble bajo el régimen de producción compartida, pero están perdiendo terreno con México quien tiene ventajas derivadas del TLCAN, menores costos salariales y menor tiempo de entrega (Gereffi, 2000: 80-85).

En el mercado de la confección de EUA participan diferentes tipos de empresas:

- Las detallistas (Wal Mart y Sears, entre otras) fueron las primeras en aprovechar las ventajas competitivas de los productores de los países con costos salariales bajos, convirtiéndose en sus principales compradores. Por lo general, no se involucran en la fabricación, sino que contratan la producción de prendas estandarizadas a fabricantes independientes en terceros países, que se responsabilizan por los materiales y la confección.

- Las comercializadoras de marca (Liz Claiborne, Nike y Polo, por citar los más importantes) trasladaron las actividades de corte, ensamble y/o confección a países subdesarrollados, reservándose el diseño exclusivo de la prenda y la comercialización.

- Los productores integrados de prendas de marca trasladaron parte de sus plantas a otros países a los que les enviaron la tela y los accesorios: en un principio a los asiáticos y en la última década a México y a algunos países de Centroamérica y el Caribe, aprovechando las cláusulas del régimen 807 y otras iniciativas del gobierno de EUA (Gereffi, 2000: 53-108).

En realidad, las empresas estadounidenses de la industria de la confección controlan la cadena productiva, convirtiéndose en la mayoría de los casos en fabricantes "sin fábrica".

\section{Características del sector textil y del vestido en México}

Este sector se caracteriza por ser intensivo en mano de obra, por lo que las diferencias en los costos salariales de un país a otro son factores muy importantes para su competitividad (Organización Internacional del Trabajo, 1994: 39-40).

Los costos de mano de obra en México representan el $22 \%$ de los de toda la cadena productiva, comparado con el 33\% de EUA e Italia, el 18\% en Brasil y el 9\% en China. Estos datos muestran lo difícil que es para México competir con China (Werner, 2003).

La Organización Internacional del Trabajo (Ibidem) en 1993 reportó los costos salariales por hora en la industria del vestido en dólares (salarios más prestaciones), los cuales fueron 
calculados por Werner International: México US\$1.08, EUA US\$ 8.13, Canadá US\$9.14, China US\$ 0,25, Hong Kong US\$3.85, Corea US\$ 2.71, Japón US\$10.64, Singapur US\$3.06, Taiwán US\$4.61, Bangladesh US\$0.16, Filipinas US\$0.53, India US\$0.27, Indonesia US\$0.28, Malasia \$0.77, Pakistán US\$0.27, Tailandia US\$0.71, Argentina US\$1.85, Brasil US\$0.73, Colombia US \$1.22, Uruguay US\$2.35 y Venezuela US\$1.48.

Asimismo, la OIT determinó lo siguiente: US\$1.08 en México, US\$1.31 en Honduras, US $\$ 1.38$ en El Salvador, US\$1.62 en República Dominicana, US\$1.80 en Jamaica y \$2.38 en Costa Rica (Chacón,2000:47).

Los datos anteriores reflejan que los salarios son más bajos en los países en desarrollo, principalmente en México en comparación con los de los países industrializados, pero son más altos que los de China, Bangladesh, Filipinas, India, Indonesia, Malasia, Pakistán, Tailandia y Brasil. Cabe destacar que los datos de los costos salariales de México se refieren al sector formal de la industria del vestido, ya que los salarios de los trabajadores del sector informal y de los trabajadores a domicilio son aun menores y no cuentan con prestaciones y seguridad social. También explican por qué países como Japón, Hong Kong, Taiwán, Corea y Singapur trasladaron sus procesos a países como China, Filipinas, India, Malasia, Pakistán y Tailandia.

Según una publicación de 2002 de la Secretaría de Economía, el mercado formal de prendas de vestir en México se encuentra concentrado en un número muy reducido de empresas (9), que concentran el 40\% de las ventas. También existe una alta concentración en la producción de productos básicos (commodities) y no en productos de moda. Las condiciones de financiamiento a las empresas de este sector son desfavorables y faltan programas gubernamentales que apoyen e incentiven la inversión en la cadena productiva textil-confección. Además, existe falta de cultura empresarial entre los directivos, lo cual origina que no se cumplan los tiempos de entrega de insumos y de productos. E1 58\% del mercado nacional de dichas prendas se abastece del contrabando, robos y del mercado informal.

En México, la industria textil está en declive y la industria de la confección está conformada por unas cuantas grandes empresas que exportan y por miles de micro y pequeñas, muchas de ellas en el sector informal, que surten al mercado interno. En 1996, de 11,000 empresas de la confección, $95 \%$ eran micro y pequeñas, $4 \%$ medianas y $1 \%$ grandes. Estos datos reflejan la fragmentación de la industria mexicana de prendas de vestir, lo cual le impide aprovechar economías de escala reduciendo su competitividad frente a productos de otros países, sobre todo de China (González M., 2004).

Es un hecho que ha entrado al mercado mexicano gran cantidad de tela y ropa importada, principalmente de origen asiático, mediante prácticas dumping, contrabando o piratería. En el estudio de Werner (2003: 24) se señalan —además de los ya mencionados- los siguientes problemas que enfrenta la industria textil y del vestido en México: subfacturación y triangulación de mercancía. Esta práctica ilegal es muy utilizada por los países asiáticos, que exportan sus productos a países con aranceles bajos, en los cuales se cambian los documentos y las etiquetas para luego ser introducidos a nuestro país. 
Poco ha podido hacer el gobierno mexicano para combatir estas prácticas desleales e ilegales a pesar de las denuncias de los empresarios, que son obstaculizadas por la lentitud de la burocracia y en ocasiones por la corrupción existente en las aduanas (Simón, 2004).

Para obtener la información que aparece en los apartados que siguen se utilizó el Sistema para Analizar el Crecimiento del Comercio Internacional (MAGIC ${ }^{6}$, por sus siglas en inglés) de la Comisión Económica para América Latina y el Caribe (CEPAL), Naciones Unidas, versión 2003. Para establecer la tipología de los productos de exportación, el MAGIC utiliza el criterio desarrollado por el sistema Competetitive Analysis of Nations (CAN) diseñado y desarrollado por la CEPAL en 1995.

La definición de los conceptos que se utilizan se presentan en el anexo, así como la gráfica de la matriz de competitividad, la clasificación de los sectores y la metodología para determinar la tipología de los productos (CEPAL, 2003).

\section{Participación de México en las importaciones de EUA}

Entre 1990 y 2002, el valor de los productos mexicanos ha aumentado su peso relativoen las importaciones de EUA, al pasar de $6.09 \%$ a $11.58 \%$, como se puede observar en el cuadro 1; asimismo, puede verse que a partir de la firma del TLCAN se aceleraron las exportaciones de productos mexicanos. En este tratado se otorgaron importantes reducciones arancelarias a las exportaciones mexicanas a EUA. En el caso de la industria del vestido, en 1993 el arancel promedio para productos de México era de 18.3\%, el cual se fue reduciendo paulatinamente hasta llegar en 1998 a 0.6\% (Gitli y Arce, 2000: 121) y en 2002 a $0.28 \%$. $^{7}$ Otro factor importante para el aumento de las exportaciones de México a EUA fue la devaluación de nuestra moneda $(100 \%$ en términos nominales y $50 \%$ en términos reales), que ocasionó un incentivo para que las empresas en México incrementaran su producción para exportar ante la disminución de los salarios pagados en dólares en nuestro país y también para que otras empresas se trasladaran a México con el consecuente traslado de la inversión (Ibidem: 112-114).

Mattar y Hernández (2000) señalan que si bien el sector exportador mexicano ha tenido un desempeño notable en la última década del siglo pasado, y en particular desde la entrada en vigencia del TLCAN, este segmento se encuentra concentrado en un número reducido de empresas, no sólo en el caso de la industria maquiladora que aporta el $45 \%$ de las exportaciones totales de bienes, sino de otras firmas que adquieren casi la totalidad de sus insumos en el exterior. Lo anterior ha ocasionado el rompimiento de cadenas productivas en la manufactura, generándose una estructura dual donde prevalece un reducido número de empresas competitivas internacionalmente y un gran número de pequeños negocios que muestran grandes problemas tanto para allegarse recursos como para producir artículos de calidad que puedan competir en los mercados tanto nacionales como internacionales.

\footnotetext{
6 "Module to analyse the Growth to Internacional Commerce" (MAGIC).

${ }^{7}$ MAGIC, 2003, CEPAL.
} 


\section{Cuadro 1}

Participación de México en las importaciones de EUA

\begin{tabular}{|l|c|r|r|r|}
\hline Año & $\begin{array}{c}\text { Importaciones } \\
\text { globales totales de } \\
\text { EUA (Miles } \\
\text { SUSD) }\end{array}$ & $\begin{array}{c}\text { Importaciones } \\
\text { totales de EUA a } \\
\text { México (Miles } \\
\text { \$USD) }\end{array}$ & $\begin{array}{c}\text { Participa- } \\
\text { ción de } \\
\text { México \% }\end{array}$ & $\begin{array}{c}\text { Balance Comercial } \\
\text { (Miles SUSD) }\end{array}$ \\
\hline 1990 & $495,269,644$ & $30,172,293$ & 6.09 & $(1,796,826)$ \\
\hline 1991 & $488,122,838$ & $31,194,292$ & 6.39 & $2,081,488$ \\
\hline 1992 & $532,352,022$ & $35,189,322$ & 6.61 & $5,408,129$ \\
\hline 1993 & $580,468,670$ & $39,929,656$ & 6.88 & $1,705,839$ \\
\hline 1994 & $663,830,137$ & $49,492,801$ & 7.46 & $1,347,464$ \\
\hline 1995 & $743,505,251$ & $61,704,998$ & 8.30 & $(15,393,543)$ \\
\hline 1996 & $791,314,697$ & $72,963,189$ & 9.22 & $(16,202,367)$ \\
\hline 1997 & $869,873,897$ & $85,829,909$ & 9.87 & $(14,451,599)$ \\
\hline 1998 & $913,884,886$ & $94,708,666$ & 10.36 & $(15,698,579)$ \\
\hline 1999 & $1,024,765,969$ & $109,706,486$ & 10.71 & $(22,662,448)$ \\
\hline 2000 & $1,216,887,535$ & $135,910,534$ & 11.17 & $(24,189,656)$ \\
\hline 2002 & $1,163,548,552$ & $134,732,185$ & 11.58 & $(37,201,572)$ \\
\hline
\end{tabular}

Fuente: elaborado con base en Comisión Económica para América Latina y el Caribe (CEPAL), Naciones Unidas, MAGIC, versión 2003

\section{Comportamiento exportador de la industria de prendas de vestir de México}

La participación del sector textil y de la confección en las exportaciones totales de México fue alrededor de $7 \%$ en 2001 y 2002, de este porcentaje el $84 \%$ corresponde a la confección. Este sector ocupa el cuarto lugar en la generación de divisas para el país, después del eléctrico-electrónico, del automotriz y del petrolero. La balanza comercial de México en el sector textil y del vestido ha pasado de ser deficitaria en 1994, a tener un saldo positivo de 2,400 millones de dólares en el 2000, debido al peso de las prendas de vestir. En 2002, el 75\% de las exportaciones de la industria textil fueron a EUA y el 95\% de las ventas externas del sector de prendas de vestir se orientaron a dicho país. Cabe destacar que la participación de la industria maquiladora en este sector es muy significativa, pues aproximadamente las dos terceras partes de sus exportaciones son realizadas por maquiladoras, que se caracterizan por su volatilidad (Agoitia, 2003).

El 75\% de las importaciones de prendas de vestir de EUA provenientes de México ingresan bajo la partida 9802.00.80, la cual establece que los productos sean fabricados con tela de EUA o de otro país, siempre que sea cortada en ese país y se exporte para ser ensamblada, pagándose la tarifa arancelaria sobre el valor agregado. La preferencia no-arancelaria sí exige que la tela sea fabricada y cortada en Estados Unidos. 
Las exportaciones mexicanas de prendas tejidas y de tejido plano a EUA se consideran representativas del sector de la confección de prendas de vestir de México y son las que mostraron el mayor dinamismo. El comercio de confecciones de punto y de tejido plano entre EUA y México se incrementó en 3588\% y 812\%, respectivamente entre 1990 y 2002. Por lo anterior, los análisis subsecuentes se realizarán con las confecciones de tejido de punto que corresponden al capítulo 61 del Sistema Armonizado de Designación y Codificación de Mercancías (SA) y con las de tejido plano al capítulo 62 del mismo Sistema (véase cuadro 2). Asimismo, se hará un análisis a diez dígitos de dichos capítulos con el fin de identificar aquellos productos que son más competitivos en EUA y cuáles son las características del mercado en el que participan.

\section{Cuadro 2}

Dinámica de las importaciones de EUA provenientes de México Industria del vestido, 1990-2002

\begin{tabular}{lrcc}
\hline $\begin{array}{l}\text { Clasificación } \\
\text { (SA) }\end{array}$ & \multicolumn{2}{c}{$\begin{array}{c}\text { Valor de las importaciones } \\
\text { (Miles de dólares) }\end{array}$} & Incremento \\
& $\mathbf{1 9 9 0}$ & $\mathbf{2 0 0 2}$ & $\%$ \\
\hline MÉXICO: & 87,389 & $3,135,118$ & 3588 \\
Capítulo 61 & 554,799 & $4,504,279$ & 812 \\
Capítulo 62 & \multicolumn{3}{c}{ Análisis a dos dígitos del SA } \\
& Fuente: elaborado con base en CEPAL, MAGIC, 2003
\end{tabular}

Como puede verse en el cuadro 3, la participación de México en la industria del vestido en EUA, por lo que respecta al capítulo 61 del SA, tuvo un gran crecimiento, pues pasó del $1.01 \%$ al $11.27 \%$ en el periodo de 1990 a 2002; en el caso del capítulo 62, se observa una tendencia similar a la del capítulo 61 para México debido a que su participación creció de 3.86 a $14.58 \%$. 


\section{Cuadro 3}

Participación de México en las importaciones de la industria del vestido en EUA (1990-2002)

\begin{tabular}{|l|r|r|}
\hline \multirow{3}{*}{ Año } & \multicolumn{2}{|c|}{ MÉXICO } \\
& GRUPO DE PRODUCTOS (SA) \\
\cline { 2 - 3 } & $\begin{array}{c}\text { Capítulo 61 } \\
\text { \% }\end{array}$ & \multicolumn{2}{c|}{ Capítulo 62 } \\
\% \\
\hline 1990 & 1.01 & 3.86 \\
\hline 1991 & 1.27 & 4.83 \\
\hline 1992 & 1.65 & 5.15 \\
\hline 1993 & 2.85 & 5.10 \\
\hline 1994 & 4.24 & 6.02 \\
\hline 1995 & 7.02 & 8.12 \\
\hline 1996 & 9.71 & 9.97 \\
\hline 1997 & 11.60 & 11.85 \\
\hline 1998 & 13.02 & 13.80 \\
\hline 1999 & 13.96 & 15.43 \\
\hline 2000 & 13.25 & 15.61 \\
\hline 2001 & 12.50 & 14.74 \\
\hline 2002 & 11.27 & 14.58 \\
\hline
\end{tabular}

Análisis a dos dígitos del SA

Fuente: elaborado con base en CEPAL, MAGIC, 2003

La estructura de las exportaciones de México a EUA se calcula dividiendo el valor de las exportaciones de cada producto o grupo de productos del país de que se trate a (EUA) entre el valor de las exportaciones totales de dicho país a EUA. En el cuadro 4 se presentan los cálculos de 1990 a 2002 para los capítulos 61 y 62. Si analizamos dicha estructura, observamos que se tiene un incremento sostenido de 1990 a 1994; de 1994 hasta 1999 —en el caso del capítulo 61 - y hasta 1998 - en el caso del capítulo 62-, el ritmo de crecimiento aumenta debido a la entrada en vigor del TLCAN, para después iniciar una caída, que coincide con la desaceleración económica de los Estados Unidos iniciada en 2000 .

\section{Cuadro 4}

Estructura de la exportación de prendas de vestir de México a EUA

\begin{tabular}{lccccccccccccc}
\hline Clasif. & 1990 & 1991 & 1992 & 1993 & 1994 & 1995 & 1996 & 1997 & 1998 & 1999 & 2000 & 2001 & 2002 \\
SA & $\%$ & $\%$ & $\%$ & $\%$ & $\%$ & $\%$ & $\%$ & $\%$ & $\%$ & $\%$ & $\%$ & $\%$ & $\%$ \\
\hline MÉXICO: & 110.29 & 0.36 & 0.48 & 0.76 & 1.04 & 1.58 & 2.00 & 2.52 & 2.98 & 3.02 & 2.57 & 2.55 & 2.33 \\
Cap.61 & 0.29 & & \\
Cap.62 & 1.84 & 2.31 & 2.63 & 2.54 & 2.56 & 2.92 & 3.13 & 3.59 & 4.10 & 4.04 & 3.77 & 3.55 & 3.34
\end{tabular}

Análisis a dos dígitos del SA

Fuente: elaborado con base en CEPAL, MAGIC, 2003 


\section{Cuadro 5}

\section{Resumen del comportamiento exportador de las industrias del vestido de México en EUA, 1990-2002}

\begin{tabular}{|c|c|c|c|c|c|c|c|}
\hline \multirow[t]{2}{*}{$\begin{array}{l}\text { Clasif. } \\
\text { Sistema } \\
\text { Armoni- } \\
\text { zado }\end{array}$} & \multicolumn{2}{|c|}{$\begin{array}{l}\text { Participación } \\
\text { importaciones } \\
\text { industria del } \\
\text { vestido de EUA }\end{array}$} & \multicolumn{2}{|c|}{$\begin{array}{l}\text { Estructura de } \\
\text { exportación }\end{array}$} & \multirow{2}{*}{$\begin{array}{l}\text { Cambio } \\
\text { de mercado } \\
\\
\%\end{array}$} & $\begin{array}{l}\text { Participación } \\
\text { del producto }\end{array}$ & \multirow[t]{2}{*}{ Tipología* } \\
\hline & $\begin{array}{c}1990 \\
\%\end{array}$ & $\begin{array}{c}2002 \\
\%\end{array}$ & $\begin{array}{c}1990 \\
\%\end{array}$ & $\begin{array}{c}2002 \\
\%\end{array}$ & & $\%$ & \\
\hline MÉXICO & & & & & & & \\
\hline Cap.61 & 1.01 & 11.27 & 0.29 & 2.33 & 10.26 & 0.65 & $\begin{array}{l}\text { Estrella } \\
\text { naciente }\end{array}$ \\
\hline Cap.62 & 3.86 & 14.58 & 1.84 & 3.34 & 10.72 & $(0.24)$ & $\begin{array}{l}\text { Estrella } \\
\text { menguante }\end{array}$ \\
\hline
\end{tabular}

Con base en la participación en el mercado de EUA, la industria mexicana reveló un comportamiento competitivo en el grupo de productos 61 que incrementaron su participación en $10.26 \%$ en un mercado dinámico (que mostró un aumento en la participación de dichos productos del $0.65 \%$ ), por lo que se le evalúa como un producto ascendente, es decir, como estrella naciente; el grupo del capítulo 62 también incrementó su participación en $10.72 \%$, pero el mercado mostró señales de estancamiento al disminuir la participación del producto en $0.24 \%$. Este análisis es útil para evaluar el desempeño exportador de México y tomar decisiones a futuro sobre el tipo de productos por exportar en función al dinamismo de sus mercados. Se considera conveniente hacer un análisis a diez dígitos del SA para determinar la tipología de cada uno de los productos que conforman los capítulos 61 y 62 .

\section{Principales productos de prendas de vestir tejidas o de punto (capítulo 61) de México que compiten en el mercado de EUA}

Utilizando el criterio de la contribución del producto, se realizó un análisis a diez dígitos del SA para identificar los productos de prendas de vestir de tejido de punto y plano más importantes en el mercado de EUA, procedentes de México en el periodo 1990-2002. Una vez identificados los productos con mayor contribución en el comercio bilateral, se determinó la tipología de los productos con base en el cambio de su participación de mercado y de la participación del producto (véanse cuadros 6 al 9).

Por lo que se refiere a prendas de vestir tejidas o de punto, en el cuadro 6 se presentan los cinco productos mexicanos que tienen una mayor proporción de su valor en el comercio 
total bilateral con EUA: camisas y pullovers de algodón para hombre y para dama (exceptuando ropa interior), así como calcetines y medias de algodón para várices. Cuatro de estos productos fueron competitivos en mercados dinámicos y se clasificaron como estrellas nacientes. Llama la atención el caso de las camisas de hombre o niño, o de punto con menos de $30 \%$ de seda, las cuales mostraron el mayor incremento $(74.10 \%)$ en su participación de mercado, pero éste mostró señales de estancamiento. Esta información proporciona bases a las empresas que exportan estos productos para tomar decisiones sobre la conveniencia de diversificar sus exportaciones a mercados que muestren mayor dinamismo (véase cuadro 7). 


\section{Cuadro 6}

Contribución de los principales productos mexicanos de prendas de vestir de tejido de punto (capítulo 61 del SA) en el mercado de EUA de 1990 a 2002

\section{Contribucióndel producto*}

\begin{tabular}{|c|c|c|c|c|c|c|c|c|c|c|c|c|c|c|}
\hline Código & $\begin{array}{l}\text { Descripción del } \\
\text { Producto }\end{array}$ & $\begin{array}{r}1990 \\
\%\end{array}$ & $\begin{array}{r}1991 \\
\%\end{array}$ & $\begin{array}{c}1992 \\
\%\end{array}$ & \begin{tabular}{l|l}
1993 \\
$\%$
\end{tabular} & $\begin{array}{r}1994 \\
\%\end{array}$ & $\begin{array}{c}1995 \\
\%\end{array}$ & $\begin{array}{c}1996 \\
\%\end{array}$ & $\begin{array}{c}1997 \\
\%\end{array}$ & $\begin{array}{c}1998 \\
\%\end{array}$ & $\begin{array}{c}1999 \\
\%\end{array}$ & $\begin{array}{c}2000 \\
\%\end{array}$ & $\begin{array}{c}2001 \\
\%\end{array}$ & $\begin{array}{c}2002 \\
\%\end{array}$ \\
\hline 6109100012 & $\begin{array}{l}\text { Camisas de algodón tejidas o de punto } \\
\text { para hombre, excepto ropa interior }\end{array}$ & 0.00 & 0.00 & 0.02 & 0.09 & 0.10 & 0.17 & 0.24 & 0.22 & 0.28 & 0.28 & 0.26 & 0.28 & 0.23 \\
\hline 6109100040 & $\begin{array}{l}\text { Camisas de algodón tejidas o de punto } \\
\text { para mujer, excepto ropa interior }\end{array}$ & 0.00 & 0.00 & 0.00 & 0.00 & 0.01 & 0.05 & 0.12 & 0.13 & 0.14 & 0.21 & 0.18 & 0.17 & 0.15 \\
\hline 6110303040 & $\begin{array}{l}\text { Camisas de hombre o niño, tejidas o de } \\
\text { punto, con menos de } 30 \% \text { de seda }\end{array}$ & 0 & 0 & 0 & 0 & 0.01 & 0.01 & 0.06 & 0.11 & 0.11 & 0.13 & 0.14 & 0.14 & 0.12 \\
\hline 6110202075 & $\begin{array}{l}\text { Pullovers de dama o niña y prendas } \\
\text { similares de algodón tejidas o de punto } \\
\text { con menos del } 36 \% \text { de lino }\end{array}$ & 0.01 & 0.00 & 0.01 & 0.01 & 0.01 & 0.02 & 0.03 & 0.04 & 0.06 & 0.07 & 0.08 & 0.11 & 0.12 \\
\hline 6115929000 & $\begin{array}{l}\text { Calcetines y medias de algodón, tejidas } \\
\text { o de punto, para várices }\end{array}$ & 0 & 0 & 0 & 0 & 0 & 0 & 0.01 & 0.07 & 0.09 & 0.10 & 0.09 & 0.10 & 0.10 \\
\hline
\end{tabular}

* Véase definición en el anexo

Análisis a diez dígitos del SA

Fuente: elaborado con base en CEPAL, MAGIC, 2003. 


\section{Cuadro 7}

Tipología de los principales productos mexicanos de prendas de vestir de tejido de punto (capítulo 61 del SA) en el mercado de EUA de 1990 al 2002

\begin{tabular}{|c|c|c|c|c|}
\hline $\begin{array}{l}\text { Código } \\
\text { Producto }\end{array}$ & Descripción del producto & $\begin{array}{c}\text { Cambio de } \\
\text { mercado } \\
\% \\
\end{array}$ & $\begin{array}{l}\text { Participación* } \\
\text { del producto } \\
\%\end{array}$ & Tipología* \\
\hline 6109100012 & $\begin{array}{l}\text { Camisas de algodón tejidas o de } \\
\text { punto para hombre, excepto } \\
\text { ropa interior }\end{array}$ & 34.80 & 0.05 & $\begin{array}{l}\text { Estrella } \\
\text { naciente }\end{array}$ \\
\hline 6109100040 & $\begin{array}{l}\text { Camisas de algodón tejidas o de } \\
\text { punto para mujer, excepto ropa } \\
\text { interior }\end{array}$ & 40.20 & 0.01 & $\begin{array}{l}\text { Estrella } \\
\text { naciente }\end{array}$ \\
\hline 6110303040 & $\begin{array}{l}\text { Camisas de hombre o niño, } \\
\text { tejidas o de punto, con menos de } \\
30 \% \text { de seda }\end{array}$ & 74.10 & $(0.00)$ & $\begin{array}{l}\text { Estrella } \\
\text { naciente }\end{array}$ \\
\hline 6110202075 & $\begin{array}{l}\text { Pullovers de dama o niña y } \\
\text { prendas similares de algodón } \\
\text { tejidas o de punto con menos del } \\
36 \% \text { de lino }\end{array}$ & 4.74 & 0.16 & $\begin{array}{l}\text { Estrella } \\
\text { naciente }\end{array}$ \\
\hline 6115929000 & $\begin{array}{l}\text { Calcetines y medias de algodón, } \\
\text { tejidas o de punto, para várices }\end{array}$ & 23.64 & 0.05 & $\begin{array}{l}\text { Estrella } \\
\text { naciente }\end{array}$ \\
\hline
\end{tabular}

* Véase definiciones en el anexo

Análisis a diez dígitos del SA

Fuente: elaborado con base en CEPAL, MAGIC, 2003

\section{Principales productos de prendas de vestir de tejido plano (capítulo 62) de México que compiten en el mercado de EUA}

Con respecto a las prendas de vestir de tejido plano (capítulo 62), también se hizo un análisis a diez dígitos para identificar cuáles fueron los principales productos de este capítulo que exportó México a EUA. En el cuadro 8 puede verse que los dos productos mexicanos del capítulo 62 que tuvieron la mayor contribución en 2002 fueron los pantalones de mezclilla de algodón, blue jeans, para dama y para hombre; asimismo, se observa que la contribución de estos productos cobra mayor importancia a partir de la firma del TLCAN; sin embargo, decrece la de pantalones de mujer en el 2002, aun cuando el mercado mantuvo su crecimiento. Los otros tres productos importantes, por el mismo concepto, fueron pantalones de algodón para hombre y mujer, pero no de mezclilla y pantalones de fibras sintéticas para hombre. Todos estos productos fueron clasificados como estrellas nacientes, es decir, que son competitivos porque aumentaron su participación en un mercado que creció (véanse cuadros 8 y 9). 


\section{Cuadro 8}

Contribución de los principales productos mexicanos de prendas de vestir de tejido plano (capítulo 62 del SA) en el mercado de EUA de 1990 a 2002

Contribución de l producto*

\begin{tabular}{|c|c|c|c|c|c|c|c|c|c|c|c|c|c|c|}
\hline $\begin{array}{l}\text { Código } \\
\text { Producto }\end{array}$ & $\begin{array}{l}\text { Descripción del } \\
\text { Producto }\end{array}$ & $\begin{array}{c}1990 \\
\%\end{array}$ & $\begin{array}{r}1991 \\
\%\end{array}$ & $\begin{array}{r}1992 \\
\%\end{array}$ & $\begin{array}{r}1993 \\
\%\end{array}$ & $\begin{array}{r}1994 \\
\%\end{array}$ & $\begin{array}{r}1995 \\
\%\end{array}$ & $\begin{array}{r}1996 \\
\%\end{array}$ & $\begin{array}{r}1997 \\
\%\end{array}$ & $\begin{array}{r}1998 \\
\%\end{array}$ & $\begin{array}{r}1999 \\
\%\end{array}$ & $\begin{array}{r}2000 \\
\%\end{array}$ & $\begin{array}{r}2001 \\
\%\end{array}$ & $\begin{array}{r}2002 \\
\%\end{array}$ \\
\hline 6204624010 & $\begin{array}{l}\text { Pantalones de mezclilla de algodón para } \\
\text { mujer, blue jeans }\end{array}$ & 0.12 & 0.16 & 0.16 & 0.14 & 0.16 & 0.24 & 0.26 & 0.34 & 0.48 & 0.52 & 0.60 & 0.63 & 0.60 \\
\hline 6203424010 & $\begin{array}{l}\text { Pantalones de mezclilla de algodón para } \\
\text { hombre, blue jeans }\end{array}$ & 0.09 & 0.17 & 0.24 & 0.30 & 0.31 & 0.41 & 0.43 & 0.45 & 0.54 & 0.63 & 0.53 & 0.55 & 0.60 \\
\hline 6203424015 & $\begin{array}{l}\text { Pantalones de algodón para hombres, no de } \\
\text { mezclilla }\end{array}$ & 0.13 & 0.16 & 0.19 & 0.22 & 0.22 & 0.25 & 0.27 & 0.34 & 0.43 & 0.43 & 0.41 & 0.30 & 0.25 \\
\hline 6204624020 & $\begin{array}{l}\text { Pantalones de algodón para mujer, no de } \\
\text { mezclilla }\end{array}$ & 0.09 & 0.11 & 0.14 & 0.12 & 0.12 & 0.12 & 0.13 & 0.20 & 0.29 & 0.25 & 0.23 & 0.18 & 0.20 \\
\hline 6203434010 & Pantalones de fibras sintéticas para hombre & 0.12 & 0.19 & 0.11 & 0.08 & 0.08 & 0.08 & 0.09 & 0.12 & 0.14 & 0.15 & 0.16 & 0.16 & 0.16 \\
\hline
\end{tabular}

* Véase definición en el anexo

Análisis a diez dígitos del SA

Fuente: elaborado con base en CEPAL, MAGIC, 2003. 


\section{Cuadro 9}

Tipología de los principales productos mexicanos de prendas de vestir de tejido plano (capítulo 62 del SA) en el mercado de EUA de 1990 al 2002

\begin{tabular}{|c|l|c|c|l|}
\hline $\begin{array}{c}\text { Código } \\
\text { Producto }\end{array}$ & Descripción del producto & $\begin{array}{l}\text { Cambio de } \\
\text { mercado } \\
\text { \% }\end{array}$ & $\begin{array}{l}\text { Participación* } \\
\text { del producto } \\
\text { \% }\end{array}$ & Tipología* \\
\hline 6204624010 & $\begin{array}{l}\text { Pantalones de mezclilla de } \\
\text { algodón para mujer, blue } \\
\text { jeans }\end{array}$ & 40.84 & 0.07 & $\begin{array}{l}\text { Estrella } \\
\text { naciente }\end{array}$ \\
\hline 6203424010 & $\begin{array}{l}\text { Pantalones de mezclilla de } \\
\text { algodón para hombre, blue } \\
\text { jeans }\end{array}$ & 40.34 & 0.08 & $\begin{array}{l}\text { Estrella } \\
\text { naciente }\end{array}$ \\
\hline 6203424015 & $\begin{array}{l}\text { Pantalones de algodón para } \\
\text { hombre, no de mezclilla }\end{array}$ & 14.79 & 0.02 & $\begin{array}{l}\text { Estrella } \\
\text { naciente }\end{array}$ \\
\hline 6204624020 & $\begin{array}{l}\text { Pantalones de algodón para } \\
\text { mujer, no de mezclilla }\end{array}$ & 7.78 & 0.08 & $\begin{array}{l}\text { Estrella } \\
\text { naciente }\end{array}$ \\
\hline 6203434010 & $\begin{array}{l}\text { Pantalones de fibras } \\
\text { sintéticas para hombre }\end{array}$ & 20.25 & 0.00 & $\begin{array}{l}\text { Estrella } \\
\text { naciente }\end{array}$ \\
\hline
\end{tabular}

* Véase definiciones en el anexo Análisis a diez dígitos del SA

Fuente: elaborado con base en CEPAL, MAGIC, 2003

El análisis a diez dígitos del SA permite ver que los productos del capítulo 62 que tuvieron mayor importancia en el comercio de México y EUA participaron en mercados que muestran crecimiento, aun cuando el análisis a dos dígitos mostró que dicho capítulo en su conjunto estuvo estancado. Puede decirse que México es competitivo en pantalones de algodón de mezclilla para hombre y mujer, los cuales mostraron un incremento sostenido en su contribución en el periodo bajo estudio, salvo el caso de los de mujer que la disminuyeron en el 2002, como ya se mencionó anteriormente.

\section{Principales países que compiten con México en el mercado estadounidense de prendas de vestir tejidas o de punto (capítulo 61)}

En el cuadro 10 se muestran los diez países que tuvieron mayor participación en el mercado de EUA prendas de vestir tejidas o de punto del capítulo 61 del SA. En 2002, México ocupó el primer lugar; China, el segundo; y Hong Kong, el tercero. Como ya mencionamos, México incrementó su participación en forma notable a partir de la firma del TLCAN. En contraste, China y Hong Kong disminuyeron considerablemente su participación de 1990 al 2002, pero juntos aún superan la de México ${ }^{8}$. Otros países asiáticos, como Taiwán y Corea, mostraron un decremento de más del $50 \%$ en el mismo periodo.

Los países centroamericanos que compiten en este rubro con México, después de China y Hong Kong, mostraron gran dinamismo en su participación, particularmente Honduras y El

\footnotetext{
${ }^{8}$ El 1o. de julio de 1997, Hong Kong fue devuelto a la República Popular China como una "Región Autónoma Especial”.
} 
Salvador, quienes aventajaron a Taiwán y Corea a partir de 2000. Sin embargo, Guatemala tuvo un menor incremento que estos países y Canadá, cuyo porcentaje de participación creció en forma sostenida hasta 1999, posteriormente disminuyó para quedar en el décimo lugar.

Cabe destacar que, de los diez países con mayor participación en este capítulo, México es uno de los dos países con salarios más bajos, sólo superando a Tailandia. Esto sugiere que la participación de México tiene como base los bajos costos de la mano de obra y las tasas arancelarias preferentes.

En la gráfica 1 se presenta la tendencia de los cinco países con la mayor participación en el mercado de prendas de vestir de EUA (capítulo 61); se observa el deterioro de las exportaciones de Hong Kong y las de China, aunque estas últimas se recuperan a partir de 2000. La pérdida de participación de estos dos países es capitalizada principalmente por México, Honduras y El Salvador como parte de la estrategia de las empresas y del gobierno estadounidense para desviar las importaciones de productos asiáticos a México, Centroamérica y el Caribe. 


\section{Cuadro 10}

Diez principales países exportadores a EUA de prendas de vestir de tejido de punto (capítulo 61, SA)

\section{Participación de mercado*, por ciento}

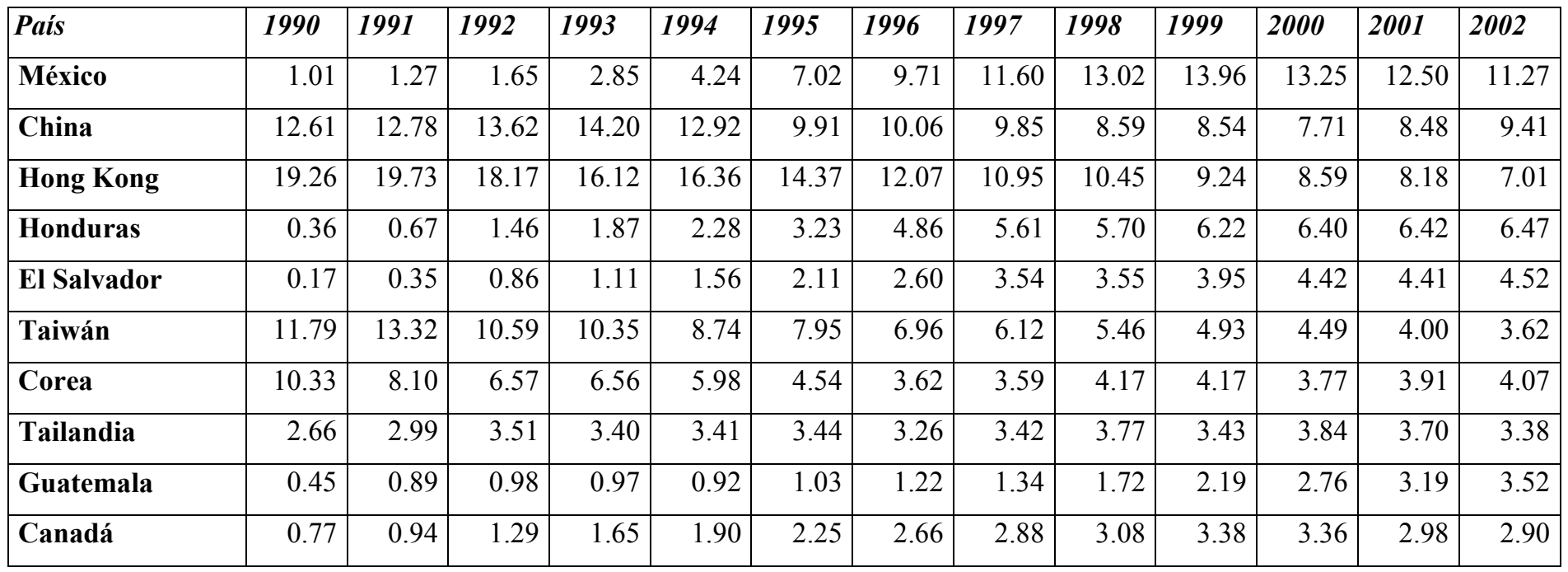

* Véase definición en el anexo

Análisis a dos dígitos del SA

Fuente: elaborado con base en CEPAL, MAGIC, 2003 


\section{Gráfica 1}

Principales países exportadores a EUA de prendas de vestir (capítulo 61 tejido de punto)

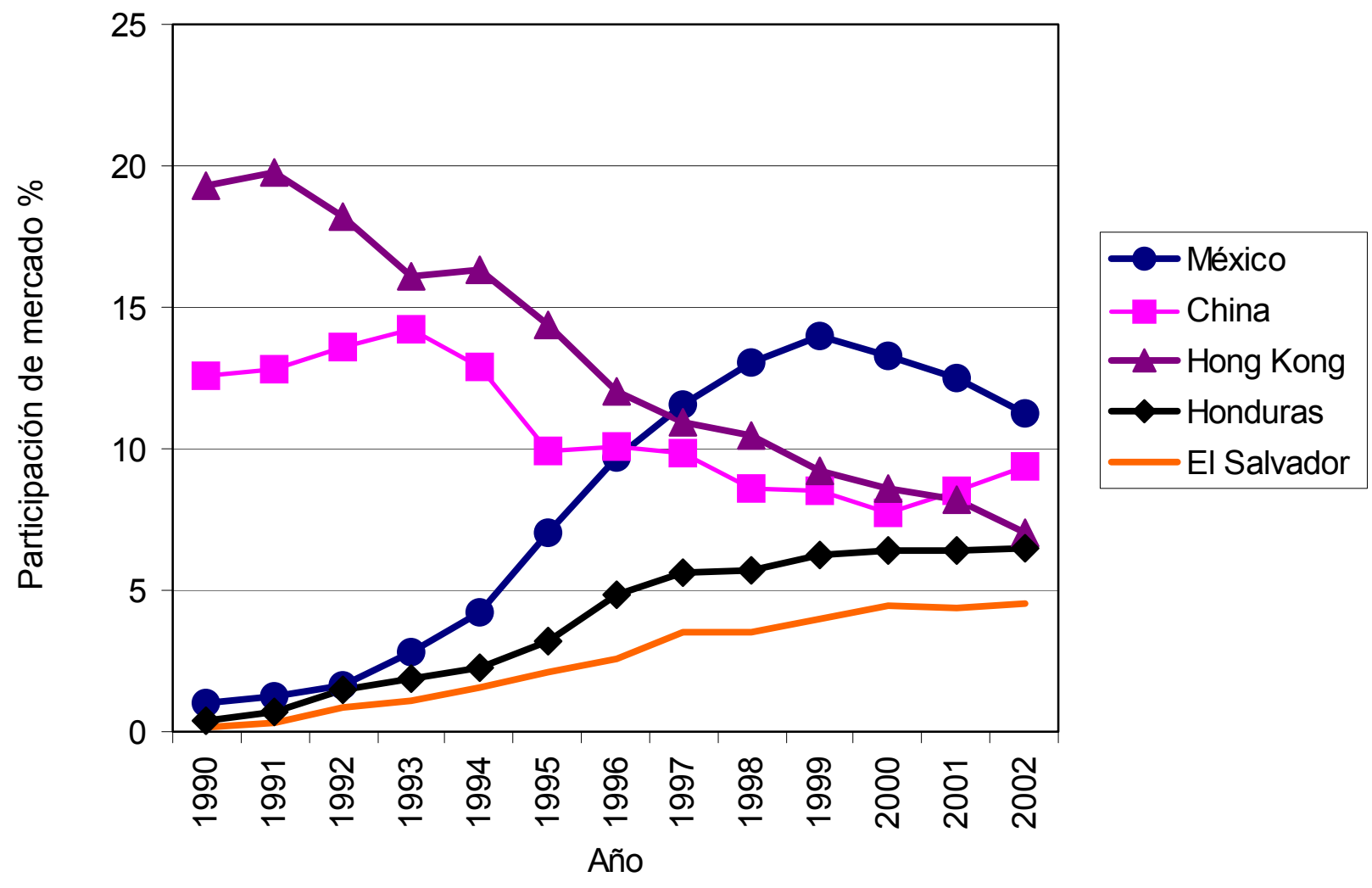

Análisis a dos dígitos del Sistema Armonizado

Fuente: elaborado con base en CEPAL, MAGIC, 2003.

Si bien es importante identificar a los principales competidores de México en relación con el grupo de productos tejidos o de punto (capítulo 61), también lo es conocer cuáles son los países que compiten con los productos de mayor contribución de México (análisis a diez dígitos del SA).

En el cuadro 11 se observa que Honduras es el país que compite en forma significativa con México, quien es líder en el mercado de EUA en camisas de algodón para hombre con 36\% de participación. Otros países que presentan menor competencia en este artículo son El Salvador, República Dominicana y Haití con porcentajes de participación del 9\%, 4.5\% y $2.5 \%$, respectivamente.

Si analizamos las tasas arancelarias para estos países, vemos que México tiene una de las dos tasas más bajas, sólo por encima de República Dominicana. Lo anterior - aunado a que México tiene los costos salariales más bajos - nos confirma el que México sustenta su competitividad básicamente en bajos salarios y preferencias arancelarias. 


\section{Cuadro 11}

Principales países que compiten con México en camisas de algodón para hombre (6109100012) en el mercado de EUA

\begin{tabular}{|l|r|r|r|r|r|}
\hline País & \multicolumn{2}{|c|}{1990} & \multicolumn{2}{c|}{200 2 } & $\begin{array}{c}\text { Tasa } \\
\text { arancelaria }\end{array}$ \\
\hline & $\begin{array}{c}\text { Valor } \\
\text { (\$USD) }\end{array}$ & $\begin{array}{c}\text { Participación } \\
\text { de mercado \% }\end{array}$ & $\begin{array}{c}\text { Valor } \\
\text { (\$USD) }\end{array}$ & $\begin{array}{c}\text { Participación } \\
\text { de mercado \% }\end{array}$ & \\
\hline México & 979,866 & 1.00 & $307,615,996$ & 35.80 & 0.28 \\
\hline Honduras & $7,958,521$ & 8.09 & $202,651,085$ & 23.58 & 0.93 \\
\hline El Salvador & 3,274 & 0.00 & $77,605,607$ & 9.03 & 1.17 \\
\hline $\begin{array}{l}\text { República } \\
\text { Dominicana }\end{array}$ & $1,987,511$ & 2.02 & $38,973,057$ & 4.54 & 0.07 \\
\hline Haití & 512,676 & 0.52 & $21,172,504$ & 2.46 & 1.50 \\
\hline
\end{tabular}

Análisis a diez dígitos del SA

Fuente: elaborado con base en CEPAL, MAGIC, 2003

\section{Principales países que compiten con México en el mercado estadounidense de prendas de vestir de tejido plano (capítulo 62)}

En el grupo de productos que forman el capítulo 62 (prendas de vestir de tejido plano) los tres países que tienen la mayor participación de mercado son México, China y Hong Kong; China ocupó el primer lugar en la participación de este mercado hasta 1997, que fue superado por México a partir de 1998; en 2001, la participación de nuestro país empieza a disminuir y en 2002 sólo supera China en $0.08 \%$. Aun cuando este país y Hong Kong disminuyeron su porcentaje en este rubro en el periodo de 1990 a 2002, la suma de su participación es mayor que la de México (véase cuadro 12).

A partir de su ingreso a la OMC, a principios de 2002, China disfrutó de dos beneficios claves: 1) EUA no obligará a China a pasar por un periodo de eliminación progresiva de diez años en las cuotas existentes, sino de cuatro y quedará libre de éstas en todos los productos que se hayan integrado a la fecha de su ingreso y 2) las cuotas existentes al término de la etapa final de eliminación se ampliarán como si China hubiera pertenecido a la OMC desde 1995. El 1o. de enero de 2005 se liberarán, entre otras, las cuotas de pantalones y los productos chinos tendrán mayor acceso al mercado de EUA a costa de los fabricantes de este país y de países extranjeros, entre ellos México que es el que tiene mayor participación en el mercado de pantalones de algodón en EUA (Werner, 2003: 49$50)$.

China ha iniciado ya una nueva ofensiva exportadora en prendas de vestir de alta calidad; tiene como ventaja los costos salariales muy inferiores a los de México y como desventaja la lejanía de EUA y mayores tasas arancelarias; aun así, prácticamente ya igualó la participación de nuestro país, como puede verse en la gráfica 2. En el caso de la participación de Hong Kong en dicho mercado, se observa una drástica caída, ya que sus 
productos están fuera de competencia porque sus salarios equivalen a más de tres veces los de México y a más de treinta veces los de China, además de estar sujeto a tasas arancelarias muy altas.

Otros países que figuran entre los diez principales en este mercado y que incrementaron su participación son: Indonesia, Bangladesh, República Dominicana, India y Sri Lanka; otros, sin embargo, como Filipinas, Italia y Corea la disminuyeron, siendo este último el que más participación perdió en el periodo estudiado, pasando de $9.41 \%$ a $2.98 \%$ (véase cuadro 12).

Cabe mencionar que en 2002 China desplazó a México como proveedor líder de EUA de productos textiles y de la confección con una participación de $12.8 \%$, mientras que la de México fue de $12.4 \%$. Con respecto al sector total de la confección, México también perdió el liderazgo en las importaciones de EUA al disminuir su participación de $13.7 \%$ en el 2001 a $13 \%$ en 2002, mientras que China, pasó al primer lugar al aumentar su participación de $12 \%$ a $13.6 \%$ (Agoitia, 2003).

En el cuadro 13 se listan los seis países que tienen la mayor participación en el mercado estadounidense de pantalones de mezclilla de algodón para mujer, producto mexicano con la mayor contribución en dicho mercado. México es el país que tiene el mayor porcentaje de participación con el 52.27\% muy lejos de Hong Kong que se encuentra en segundo lugar con el 7.66\%. Canadá, China, Macao y Cambodia le siguen con menos del 5\% cada uno.

Jennifer Bair y Gary Gereffi (2001: 1889) al respecto señalan que: "En 1999, Estados Unidos importó más de 2.6 billones de pantalones de México, representando el 34\% del total de prendas de vestir de su vecino del sur (USITIC, 2001). ${ }^{9}$

\footnotetext{
${ }^{9}$ USITIC (United States Internacional Trade Comisión, 2001). Estadísticas oficiales de la oficina de textiles
} del Departamento de Comercio de EUA, disponible en www.usec.gob 


\section{Cuadro 12}

Diez principales países exportadores de prendas de vestir de tejido plano

(capítulo 62, SA)

Participación de mercado*, por ciento

\begin{tabular}{|c|c|c|c|c|c|c|c|c|c|c|c|c|c|}
\hline País & 1990 & 1991 & 1992 & 1993 & 1994 & 1995 & 1996 & 1997 & 1998 & 1999 & 2000 & 2001 & 2002 \\
\hline México & 3.86 & 4.83 & 5.15 & 5.10 & 6.02 & 8.12 & 9.79 & 11.85 & 13.80 & 15.43 & 15.61 & 14.74 & 14.58 \\
\hline China & 14.70 & 15.47 & 17.11 & 19.07 & 16.67 & 14.75 & 15.35 & 16.01 & 13.54 & 13.07 & 12.70 & 13.10 & 14.50 \\
\hline Hong Kong & 15.34 & 14.74 & 13.35 & 11.21 & 11.06 & 10.20 & 9.22 & 7.43 & 7.76 & 7.27 & 6.78 & 6.32 & 6.32 \\
\hline Indonesia & 3.10 & 2.85 & 3.31 & 3.65 & 3.58 & 3.92 & 4.30 & 4.36 & 4.25 & 4.40 & 4.57 & 5.05 & 4.71 \\
\hline $\begin{array}{l}\text { República } \\
\text { Dominicana }\end{array}$ & 3.53 & 4.58 & 4.75 & 5.13 & 5.45 & 5.55 & 5.17 & 5.78 & 5.35 & 4.92 & 4.68 & 4.57 & 4.40 \\
\hline India & 3.89 & 3.72 & 4.14 & 4.18 & 4.71 & 4.07 & 4.10 & 3.90 & 3.95 & 3.96 & 4.20 & 4.03 & 4.46 \\
\hline Filipinas & 4.64 & 4.29 & 4.16 & 4.24 & 4.21 & 4.27 & 4.02 & 3.70 & 3.73 & 3.70 & 3.61 & 3.71 & 3.36 \\
\hline Italia & 3.98 & 3.89 & 3.30 & 3.02 & 3.24 & 3.70 & 4.15 & 3.86 & 3.80 & 3.62 & 3.18 & 3.24 & 3.34 \\
\hline
\end{tabular}

* Véase definición en el anexo

Análisis a dos dígitos del SA

Fuente: elaborado con base en CEPAL, MAGIC, 2003 


\section{Gráfica 2}

Principales países exportadores a EUA de prendas de vestir (capítulo 62 tejido plano)

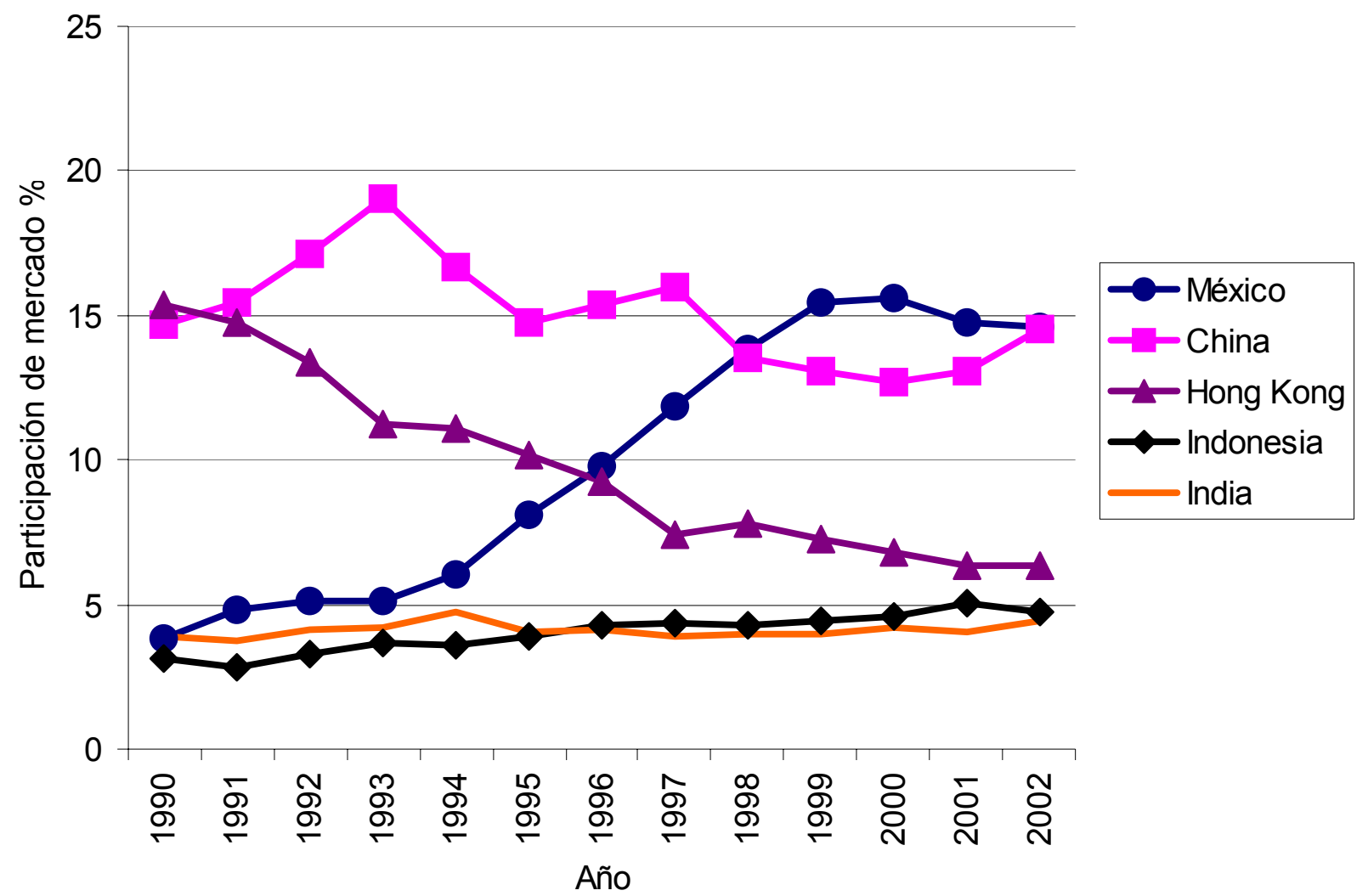

Análisis a dos dígitos del Sistema Armonizado

Fuente: elaborado con base en CEPAL, MAGIC, 2003 


\section{Cuadro 13}

Principales países que compiten con México en pantalones de mezclilla de algodón para mujer, blue jeans (6204624010) en el mercado de EUA

\begin{tabular}{|l|r|r|r|r|r|}
\hline País & \multicolumn{2}{|c|}{1990} & \multicolumn{2}{c|}{2000} & $\begin{array}{c}\text { Tasa } \\
\text { arancelaria }\end{array}$ \\
\hline & $\begin{array}{c}\text { Valor } \\
\text { (\$USD) }\end{array}$ & $\begin{array}{c}\text { Participación } \\
\text { de mercado \% }\end{array}$ & $\begin{array}{c}\text { Valor } \\
\text { (\$USD) }\end{array}$ & $\begin{array}{c}\text { Participación } \\
\text { de mercado \% }\end{array}$ & \\
\hline México & $36,329,743$ & 11.42 & $808,454,350$ & 52.27 & 0.78 \\
\hline Hong Kong & $124,900,133$ & 39.27 & $118,450,772$ & 7.66 & 16.79 \\
\hline Canadá & 172,693 & 0.05 & $68,273,725$ & 4.41 & 0.01 \\
\hline China & $10,087,871$ & 3.17 & $60,114.359$ & 3.89 & 16.75 \\
\hline Macao & $3,835,700$ & 1.21 & $30,777,718$ & 2.25 & 16.80 \\
\hline Cambodia & 0 & 0 & $27,803,886$ & 2.84 & 16.80 \\
\hline
\end{tabular}

Análisis a diez dígitos del SA

Fuente: elaborado con base en CEPAL, MAGIC, 2003.

Del análisis del cuadro 11, se observa que las tasas arancelarias de México y Canadá son las más bajas derivadas de las ventajas que les otorga el TLCAN. Resalta el hecho de que los pantalones de mezclilla para mujer que provienen de los demás países están gravados con tasas superiores al 16\%. El país que tiene el costo salarial más bajo es China, seguido por México. Podemos concluir que, también en este caso, México basa su competitividad en bajos salarios y tasas arancelarias menores que sus competidores. En 2005 se eliminarán las cuotas y las restricciones arancelarias para China; sus productos seguramente tendrán menor costo y constituirán una fuerte competencia para los de México.

\section{Conclusiones}

Del análisis realizado utilizando la base de datos Magic (CEPAL, 2003) se desprenden las siguientes conclusiones:

- De 1990 a 2002, México incrementó notablemente su presencia en el mercado de EUA debido principalmente a los siguientes factores: a) el TLCAN, que entró en vigor el 1o. de enero de 1994, le otorgó a nuestro país preferencias de acceso al mercado estadounidense, mientras que sus principales competidores seguían sujetos a restricciones de aranceles y cuotas; b) la devaluación del peso en diciembre de 1994, la cual disminuyó aún más los salarios en términos reales y abarató las exportaciones mexicanas; c) la cercanía a los principales mercados estadounidenses; y d) salarios relativamente bajos. Sin embargo, desde el inicio de la desaceleración económica de EUA a mediados de 2000, los productos mexicanos de prendas de vestir disminuyeron su participación en dicho mercado ante una restricción de la demanda originada por la recesión y el incremento de la competencia internacional 
principalmente de China después de su ingreso a la OMC y de los países de la Cuenca del Caribe que se vieron favorecidos por el Programa de Acceso Especial.

- Por lo que se refiere a las prendas de vestir de tejido plano (capítulo 61 del Sistema Armonizado), las exportaciones mexicanas a Norteamérica mostraron un gran dinamismo durante el periodo de 1990 a 2002, ocupando el primer lugar de participación en el mercado de EUA de 1997 al 2002, desplazando a China y a Hong Kong que ocuparon segundo y tercer lugar, respectivamente. Lo anterior se explica en parte porque la industria y el gobierno de Estados Unidos se orientaron a favorecer instrumentos de política comercial como el TLCAN, el Acuerdo del Textil y del Vestido y el Programa de Acceso Especial de la ICC. Uno de los objetivos de estos instrumentos fue proteger la industria textil de EUA al otorgar trato preferencial en cuotas $y$ aranceles a países que utilizan insumos estadounidenses en la fabricación de prendas de vestir, como México y los de la Cuenca del Caribe. Los competidores asiáticos (China, Hong Kong, Taiwán y Corea) resintieron el efecto de los instrumentos mencionados en su participación en dicho mercado; Honduras y El Salvador, cuyas exportaciones a EUA tienen un alto contenido de tela fabricada en este país, ocuparon el cuarto y quinto lugar de participación desplazando a Taiwán y Corea.

- Las prendas de vestir mexicanas tejidas o de punto que tuvieron en 2002 la más alta contribución - es decir, la mayor proporción de su valor en el comercio total bilateral con EUA - fueron, en primer lugar, camisas de algodón para hombre y mujer, seguidas de camisas de hombre de seda y niño con menos de $30 \%$, pullovers de dama y niña de lino con menos del $36 \%$ y calcetines y medias de algodón para várices. En el periodo 1990-2002, las camisas de hombre y niño de seda con menos de $30 \%$ fueron las que más aumentaron su participación de mercado, pero éste mostró señales de estancamiento, a diferencia de los demás productos mencionados que aumentaron su participación en mercados que crecieron.

- Los países que compitieron significativamente con las camisas de algodón para hombre - uno de los productos de México con mayor participación en el mercado de EUA - fueron Honduras y El Salvador. Nuestro país tiene como ventaja competitiva con respecto a estos países menores tasas arancelarias y costos salariales más bajos.

- Los productos mexicanos de tejido plano (capítulo 62 del SA) que destacaron por su contribución en el mercado de EUA fueron pantalones de mezclilla de algodón (blue jeans) para mujer y para hombre; dicha contribución aumentó considerablemente a partir de la firma del TLCAN, notándose un decremento en la de pantalones para mujer en el 2002, cuyo mercado mantuvo su crecimiento.

- El país que compite significativamente con México en productos de tejido plano es China, quien ocupó el primer lugar en la participación del mercado de EUA hasta 1997, siendo superado por México a partir de 1998. Sin embargo, se observó que China prácticamente ya igualó la participación de nuestro país en el 2002, lo cual puede explicarse por los beneficios que obtuvo al integrarse a la OMC; el 1o. de 
enero de 2005 se liberarán las cuotas de pantalones, entre otros productos, lo cual implica que los productos chinos tendrán mayor acceso al mercado de EUA y es muy probable que rebase la participación de México.

La industria mexicana de prendas de vestir es competitiva en el mercado de EUA en la fabricación de productos básicos (commodities) vulnerables a la competencia de precios, basando su competitividad principalmente en preferencias arancelarias y salarios bajos. En los dos últimos años se observa una disminución de su participación en dicho mercado y se espera una presión cada vez mayor de la competencia de los productos chinos, quienes tienen costos más bajos que los de México y se han visto favorecidos por el ingreso de China a la OMC con la disminución de aranceles y la eliminación de cuotas.

Nuestra industria del vestido es vulnerable porque las dos terceras partes de sus exportaciones del vestido a Estados Unidos las realizan las maquiladoras, que se caracterizan por su movilidad. Además, esta industria es dependiente de la economía de Norteamérica porque en 2002 el $75 \%$ de las exportaciones de la industria textil fueron a EUA y el $95 \%$ de las ventas externas del sector de prendas de vestir se orientaron a dicho país.

La demanda de productos de la industria de la confección está determinada por el consumidor y fluctúa según los dictados de la moda. La diferenciación de productos y la respuesta rápida de los productores a los cambios de la demanda serán los factores de éxito en la competencia del mercado estadounidense. En este sentido, México tiene la ventaja de su ubicación geográfica, pero debe incrementar su capacidad de fabricar productos de moda con mayor valor agregado de manera más rápida, más barata y con mayor variedad.

En los diversos cuadros elaborados puede observarse un incremento en la participación en el mercado de prendas de vestir de EUA tanto de México como de los países de la Cuenca del Caribe, cuyos productos tienen un alto contenido de tela y otros insumos estadounidenses. El 75\% de las importaciones de prendas de vestir de EUA provenientes de México ingresan bajo el esquema de producción compartida, lo cual implica que no incorporan tela mexicana.

La industria textil y del vestido de México enfrenta serios problemas derivados de las prácticas desleales e ilegales de comercio por parte de países asiáticos como dumping, contrabando, piratería, subfacturación y triangulación de mercancía. El gobierno mexicano no ha realizado acciones efectivas para detener la invasión de productos asiáticos que han provocado el cierre de muchos talleres al no poder competir en precios. En el caso de China, llama la atención los bajos precios de sus productos, pues aun cuando tiene la ventaja de menores costos salariales, tiene la desventaja de la lejanía y de altas tasas arancelarias.

A pesar de los graves problemas por los que atraviesa la industria textil y del vestido en México, ésta es gran generadora de empleos. Por lo tanto, es muy importante que el gobierno mexicano y los empresarios diseñen una política industrial activa tendiente a fortalecer toda su cadena productiva, aprovechando sus ventajas competitivas como son la proximidad al mercado de estadounidense, mano de obra de buena calidad y barata y tasas 
arancelarias preferenciales en dicho mercado; asimismo, diseñando estrategias para orientarse a la fabricación de paquete completo, para lo cual tiene que fortalecerse la producción de tela y de otros insumos. México debe crear vínculos con los compradores y proveedores de los países desarrollados, en particular con los de EUA, para aprender y aprovechar las oportunidades que les permita a las empresas de la cadena sobrevivir y crecer.

\section{ANEXO}

A continuación se presentan las definiciones de los principales conceptos utilizados en este artículo; cabe aclarar que cuando se menciona al socio comercial nos referimos a México. Asimismo, se presenta la matriz de competitividad, la clasificación de los sectores y la tipología de los productos (CEPAL, 2003).

Importaciones globales totales: se refiere a las importaciones de EUA de todos los productos a todos los países.

Importaciones totales de EUA: son todas las importaciones de EUA de todos los productos a un socio comercial.

Valor: es el valor monetario en dólares del intercambio comercial entre EUA y el socio comercial.

Contribución del producto: es la proporción del valor que representa un producto específico en el valor del comercio total, es decir, de todos los productos comerciados entre EUA y el socio comercial.

Participación de un socio comercial en el mercado de prendas de vestir de EUA: es igual a las exportaciones de prendas de vestir del socio comercial a EUA entre el total de las importaciones de prendas de vestir de EUA.

Participación de un producto: es el cociente de dividir las importaciones del producto que EUA realizó a todos los países entre las importaciones totales globales de EUA.

Tipología del producto: se utiliza una clasificación derivada de un análisis de competitividad basado en la metodología del sistema CAN. La metodología consiste en clasificar los productos que EUA importa según la dinámica de: a) la participación del producto y b) la de participación de mercado. Según el signo de estos dos efectos se construye una matriz de competitividad que permite clasificar los diversos sectores según su competitividad específica en el mercado de EUA. Los sectores pueden ser como sigue:

Sectores dinámicos: son aquellos que aumentan su importancia relativa en los flujos comerciales entre un año base y un año final. Productos dinámicos son los que tienen un crecimiento mayor que el promedio en términos de valor importado. 
Sectores estancados: son los que disminuyen su importancia relativa en los flujos comerciales entre un año base y un año final. Son sectores estancados aquéllos con un crecimiento igual o menor que el promedio en términos de valor importado.

Sectores competitivos: aumentan su participación del mercado entre un año base y un año final.

Sectores no competitivos: disminuyen su participación del mercado entre un año base y un año final ${ }^{10}$.

En la figura 1 se muestran las tipologías de los productos que se obtienen de la combinación de ambas dinámicas:

Figura 1

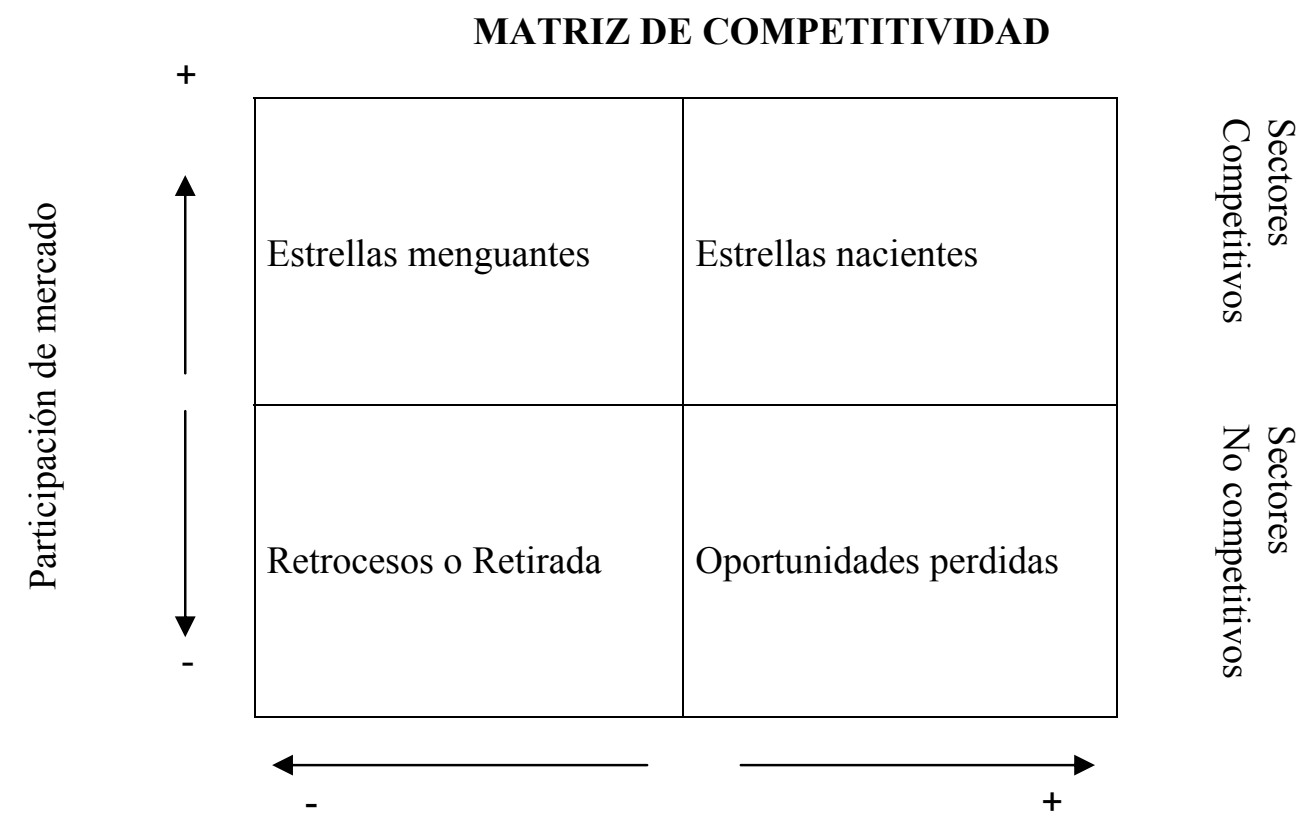

Sectores estacionarios

Sectores dinámicos

Participación del producto

Fuente: CEPAL, 2003, Manual del Usuario, MAGIC, 2003

Las clasificaciones de los sectores en la matriz de competitividad se definen como sigue:

Sectores competitivos dinámicos (estrella naciente): se incrementa la participación de mercado y éste muestra crecimiento.

\footnotetext{
${ }^{10}$ Esta metodología ha sido utilizada para evaluar la posición de los países del Istmo Centroamericano, Belice y República Dominicana en el mercado de EUA (Padilla, 2000 y Dussel, 2001), el comportamiento de la industria del vestido de México y China en el mercado de EUA (Simón y Rueda, 2004) y para evaluar la competitividad de los productos siderúrgicos mexicanos (Álvarez, 2002).
} 
Sectores competitivos estancados (estrella menguante): se incrementa la participación de mercado pero éste da señales de estancamiento.

Sectores no competitivos pero dinámicos (oportunidades perdidas): disminuye la participación de mercado y éste crece.

Sectores no competitivos y estancados (retirada o retroceso): disminuye la participación de mercado y éste se encuentra estancado.

\section{Bibliografía}

Agoitia Gil, Juan Carlos, “Análisis sectorial. Sector textil-confección: evolución reciente y perspectivas" México, Bancomext, mayo de 2003, en http://www.bancomext.com.mx, fecha de consulta 6 de junio de 2003.

Álvarez Medina, María de Lourdes, "Competitividad, comercio exterior y tecnología de la industria siderúrgica integrada en México" en Nadima Simón e Isabel Rueda (coordinadoras) Globalización y Competitividad. La industria siderúrgica en México, México, 2002, Miguel Ángel Porrúa Editores/Facultad de Contaduría y Administración-Instituto de Investigaciones Económicas, UNAM.

Bair, Jennifer and Gary Gereffi, "Local clusters in global chains: The causes and consequences of export dynamism in Torreon's blue jeans industry", en World Development, vol. 39, No 11, 2001, Elsevier Science Ltd, Pergamon, Great Britain, pp 1885-1903.

Buitelaar Rudolf, Ramón Padilla y Ruth Urrutia, Centroamérica, México y República Dominicana: Maquila y transformación productiva, Santiago de Chile, Cuadernos de la CEPAL, Naciones Unidas, 1999.

Buitelar Rudolf y Ennio Rodríguez (editores), Impacto del TLCAN en las exportaciones de prendas de vestir de los países de América Central y República Dominicana, México, Instituto para la integración de América Latina y el Caribe, BID y Sede Subregional en México de la Comisión Económica para América Latina y el Caribe (CEPAL), 2000.

Chacón, Francisco, "Comercio internacional de los textiles y el vestido: Reestructuración global de las fuentes de oferta en EE.UU. durante la década de los noventa" en Buitelar Rudolf y Ennio Rodríguez (editores), Impacto del TLCAN en las exportaciones de prendas de vestir de los países de América Central y República Dominicana, México, Instituto para la integración de América Latina y el Caribe, BID y Sede Subregional en México de la Comisión Económica para América Latina y el Caribe (CEPAL), 2000, p.p. 19-20. 
CEPAL, Manual del Usuario del Sistema para Analizar el Crecimiento del Comercio Internacional, MAGIC, versión 2003.

Dussel, Enrique, Un análisis de la competitividad de las exportaciones de prendas de vestir de Centroamérica utilizando los programas y la metodología CAN y MAGIC, México, Serie Estudios y Perspectivas de la Unidad de Desarrollo Industrial de la CEPAL, Naciones Unidas, julio de 2001.

Gereffi, Gary, "La transformación de la industria de la indumentaria en América del Norte: es el TLCAN una maldición o una bendición?" en Buitelar Rudolf y Ennio Rodríguez, editores, Impacto del TLCAN en las exportaciones de prendas de vestir de los países de América Central y República Dominicana, México, Instituto para la integración de América Latina y el Caribe, BID y Sede Subregional en México de la Comisión Económica para América Latina y el Caribe (CEPAL), 2000, p.p. 53-108.

Gitli, Eduardo y Arce, Randall, "Los desbalances de los países de la Cuenca del Caribe frente al TLCAN: La industria de la confección" en Rudolf Buitelaar y Ennio Rodríguez (editores), Impacto del TLCAN en las exportaciones de prendas de vestir de los países de América Central y República Dominicana, México, Instituto para la integración de América Latina y el Caribe, BID y Sede Subregional en México de la Comisión Económica para América Latina y el Caribe (CEPAL), 2000.

González Marín, María Luisa, "Efectos del TLCAN en la industria textil y de la confección mexicana" en Isabel Rueda, Nadima Simón y Ma. Luisa González Marín (coordinadoras), La industria de la confección en México y China ante la globalización, México, Miguel Ángel Porrúa, IIEc, FCA, UNAM, 2004.

Máttar, Jorge y René A. Hernández, "Las políticas macroeconómicas y el entorno legalinstitucional en la industria maquiladora de exportación de México y Centroamérica" en Rudolf Buitelaar y Ennio Rodríguez (editores), Impacto del TLCAN en las exportaciones de prendas de vestir de los países de América Central y República Dominicana, México, Instituto para la integración de América Latina y el Caribe, BID y Sede Subregional en México de la Comisión Económica para América Latina y el Caribe (CEPAL), 2000.

Oficina Internacional del Trabajo, Situación reciente en la industria del vestido, Ginebra, OIT, 1994.

Padilla, Pérez Ramón, "La posición de los países del Istmo Centroamericano, Belice y República Dominicana en las importaciones de EE.UU.” en Rudolf Buitelaar y Ennio 
Rodríguez (editores), Impacto del TLCAN en las exportaciones de prendas de vestir de los países de América Central y República Dominicana, México, Instituto para la integración de América Latina y el Caribe, BID y Sede Subregional en México de la Comisión Económica para América Latina y el Caribe (CEPAL), 2000.

Simón, Nadima, "Prácticas desleales e ilegales de comercio internacional en las industrias de textiles y prendas de vestir en México" en Isabel Rueda, Nadima Simón y Ma. Luisa González Marín (coordinadoras), La industria de la confección en México y China ante la globalización, México, Miguel Ángel Porrúa, IIEc, FCA, UNAM, 2004.

Simón, Nadima y Rueda, Isabel, "Comportamiento de la industria del vestido de México y China en el mercado de Estados Unidos” en Isabel Rueda, Nadima Simón y Ma. Luisa González Marín (coordinadoras), La industria de la confección en México y China ante la globalización, México, Miguel Ángel Porrúa, IIEc, FCA, UNAM, 2004.

Secretaría de Economía, "Programa para la competitividad de la cadena fibras-textilvestido", México, 2002.

Werner International, Competitividad de la Industria Textil en México y Análisis Comparativo ("benchmark") Contra las Mejores Prácticas del Mundo, México, Cámara Nacional de la Industria Textil, 2002. 